\title{
The Impact of Herd Behavior on the Chinese Stock Market
}

\author{
Yuanzhi Lei \\ ${ }^{1}$ Duke Kunshan University, Applied Mathematics, Kunshan, Jiangsu, China, 215316 \\ Email: yl683@duke.edu
}

\begin{abstract}
Herd behavior refers to an individual who is influenced by the behavior of the outside crowd, and shows his own perception, judgment, and cognition opinion or the behavior of the majority of people. In behavioral finance, herding is always used to describe similar investment choices due to mutual influence among investors. It happens at the same time with market volatility, which exists in both up and down markets. This article investigates the existence of herd behavior in the Chinese stock market and the impact of herd behavior in the Chinese finance market. Concluding the studies that make use of the nonlinear model of Christie and Huang ( $\mathrm{CH}$ Model) and Chang, Cheng, and Khorana (CCK model). Evidence of herding is found in Chinese stock market. It is shown that herding is influencing Chinese stock market for decades from both sides.
\end{abstract}

Keywords: Herd behavior, Chinese finance market, cross-sectional standard deviation

\section{INTRODUCTION}

Many related pieces of research including Christie and Huang[1] Chang et al.[2] have already proved that herd behavior exists among investors around the world applying cross-sectional standard deviation (CSSD) or cross-sectional absolute deviation (CSAD). However, in different regions, the result of searching for herd behavior turned out to be different. According to Chiang and Zheng[3], herding exists in advanced stock markets except for the US and in the Asian market. This paper is motivated by the following reasons. First, though we have research literature that includes (Chong et al. [4]; Demirer and Kutan[5]; Tan et al.[6]) targeted at the Chinese market, their research orientations are slightly different and their conclusions are various. Therefore, it is vital to make a summarization for the convenience of future studies. The second reason is the unique characteristic of the Chinese stock market. According to a comparison of shanghai-Hong Kong market operation mechanism differences published by the Shanghai stock exchange (SSE), in 2014, In Shanghai, A-share market, the shareholding ratio of the individual investor reached up to $81 \%$. Owing to the immaturity of the Chinese market, the considerably high shareholding ratio of the individual investor is a big colony that could be influenced by the herd effect.
The article is organized as follows. The second section studies the presence of herding behavior in the Chinese stock market. Section 3 discusses the impact of herding in the Chinese stock market. Section 4 presents the models used in studies of herding behavior. Section 5 discusses further influences of herd behavior in the context of China. Section 6 concluded the paper and discusses the limitation and future research direction.

\section{THE EXISTENCE OF HERDING IN THE CHINESE FINANCE MARKET}

Black[7] once argued that individual investors tend to trade based on false or distorted information irrelevant to company fundamentals, and their trading behavior was random, so he defines them as noise traders, which mean Investors who have no access to inside information, regarding noise as information to trade. What's more, he also claims that such behavior distorts prices in the short term and makes rational investors incapacitate in shortterm markets.

In the context of China, noise trader is an important factor that cannot be ignored in the stock market. Also, there are many problems that remain unsolved include information lack of transparency, low efficiency caused by noise trading, and the market value of stock deviated from its intrinsic value. These are all potential factors of 
herd behavior. Therefore, it is necessary to investigate herding in the Chinese finance market.

According to previous studies of herd behavior in China, the result of different researches turned out to be different. Tan et al. collected daily data from 1994 to 2003 and used the CCK model, which is one of the most widely used models, to analyse its data. The result of this study reveals the existence of herding in both the A-share and B-share markets of China and the asymmetric effect of stock returns, trading volume, and volatility. Chiang et al., which also collect daily data from 1996 to 2007, using the CCK model with its modification. When OLS method was used, herd phenomenon was found in both Shanghai and Shenzhen A-share markets, but no herd phenomenon was found in B-share markets. Moreover, A-share investors have shown a herd mentality in both rising and falling markets. Through quantile regression analysis, we found herding phenomenon in the two exchanges under the condition of return dispersion in the low quantile region In Chong, Liu, and $\mathrm{Zhu}$, daily returns are also examined by the CCK model. The selected time range begins from January 2000 to December 2011. There was significant evidence of herding behavior throughout the sample period and in extreme market conditions in October 2007 and October 2008. In addition, they examined the impact of government intervention, the information environment, speculation and systemic risk on herds. The study found that analysts following suit can lead to herding, with herding behavior mainly concentrated in companies with high turnover or high systemic risk. However, they found no evidence that herding is related to firm size, and no significant differences in herding between SOEs and non-SOEs.

According to Yu Zhang [8], "the widely used LSV model enables us to examine the level of herd behavior among Chinese investors. The obtained results show that obvious herd behavior exists in the Chinese security market. A series of analyses were taken both for the behavior of individuals and institutional investors. The prevalence of herd behavior is based on the theory of external payment, reputation, incomplete information, and group psychology according to some research papers. As herd behavior involves multiple investment subjects, it has a significant influence on the stability and efficiency of the security market, as well as has a close relationship with the financial crisis. Behavioral finance is a finance and psychology interdiscipline that ensures the role of psychological factors of market participants in decision making, rejects traditional financial theory, and is more in line with the actual situation in financial markets. Investors, including institutional and individual ones, can achieve investment objectives based on the strategy because of the irrational behavior."

On the contrary, according to Fu and Lin [9], which adopted monthly data from 2006 to 2009 , using $\mathrm{CH}$ and
CCK models to examine, the result turned out that "herding is not found in the Chinese stock market but the asymmetric effect is found with the prevalence of herding in upmarket than in the down market." Besides, Demirer and Kutan detected no evidence of herd behavior as well.

Plausibly, many evidences show that the herd behavior widely exists in China from many researches that are relatively convincing, however, it is true that some researches do not find or find little evidence of the existence of herd behavior, and we cannot easily identify the reason behind. In that case, a more comprehensive analysis of herding in the Chinese stock market is necessary.

\section{THE IMPACT OF HERD BEHAVIOR IN THE CHINESE FINANCE MARKET}

In recent two decades, there is a large number of researches, trying to investigate herding. However, most of the related studies focused on examining the existence of herd behavior in several markets (Christie and Huang; Chang et al.; Chiang and Zheng, etc.). As for the Chinese stock market, there are fewer studies about herding, much less the reasons behind herding in China. Hence, it is relatively hard to investigate herding regarding China specifically.

We have found some papers that analyse drives behind the herd effect and its impact on the stock market generally. The perspectives on whether herding is good for the market turn out to be diverse. Some believe that herding results in a greater deviation from the intrinsic value of a certain stock (Spyrou, [10]; Bikhchandani and Sharma, [11]), while others believe herding is making the market more efficient since the price can adapt to more recent information (Hirshleifer et al., [12], Hirshleifer and Teoh, [13]).

Since, one of the most common ways of herding is to mimic earlier trades. A large amount of irrational investment will be made and the time interval between trades will cause a significant impact on the stability of the stock market because of the timeliness of the information. Nevertheless, another perspective is also provided. Although Hirshleifer et al. recognized that "the sequential nature of information arrival has a significant effect on both the trading decisions and the types of information collected by investors". Hedge fund and mutual fund managers could possibly exploit the herding behavior of individual investors, which is the largest irrational investing group in China. In this way, some researchers regard herding as an important characteristic of the finance market, which explains the predictability in securities markets and helps the market adjust itself.

Regarding the special case of Chinese stock market, individual investors is a much larger investing group than any other groups in China. Hence, herd behavior would be more likely to take place in China, especially between 
these irrational investors. Also, due to the imperfect of Chinese stock market and the timeliness difference in information, China is seriously affected by the ubiquity of herd behavior, and plenty of instability exists. However, the continuous expansion of Chinese financial markets proved the stability of Chinese stock market over a long time span. In this way, herding helps market to adjust itself is plausible.

In spide of herd behavior, the impact of foreign investors, the existence of institutional herding, important political decision-making is having quite a bit of impact on Chinese stock market. Therefore, for the convenience of further researches, we need to consider these factors in advance.

\section{CH MODEL AND CCK MODEL}

There exist two commonly used methods for detecting herding behavior using cross-sectional data on stock returns: the $\mathrm{CH}$ model and the CCK model. In fact, the $\mathrm{CCK}$ model is an improved version of the $\mathrm{CH}$ model since it is based on the theory of the $\mathrm{CH}$ model. CCK proposes the cross-sectional absolute deviation, which is measured by:

$$
\mathrm{CSADt}=1 / \mathrm{N} \sum \mathrm{i}=1 \mathrm{~N}|\mathrm{Ri}, \mathrm{t}-\mathrm{Rm}, \mathrm{t}|
$$

where $\mathrm{N}$ is the number of firms in the aggregate market portfolio, $\mathrm{Ri}, \mathrm{t}$ is the observed stock return for firm $\mathrm{i}$ on day $\mathrm{t}$ and $\mathrm{Rm}, \mathrm{t}$ is the return of market portfolio at time $\mathrm{t}$.

Then, we modify CCK's specifications and write:

$$
\mathrm{CSADt}=\gamma 0+\gamma 1 \mathrm{Rm}, \mathrm{t}+\gamma 2|\mathrm{Rm} ; \mathrm{t}|+\gamma 3 \mathrm{R} 2 \mathrm{~m}, \mathrm{t}+\delta \mathrm{t}
$$

Where CSADt is a measure of return dispersion, $\mathrm{Rm}, \mathrm{t}$ is the value of an equally weighted realized return of all industry indexes on day $\mathrm{t}$, and $|\mathrm{Rm}, \mathrm{t}|$ is the absolute term.

CCK pointed out that a reasonable asset pricing model means that there is a linear relationship between the diversification of individual asset returns and market portfolio returns. As the absolute value of market returns increases, so should the dispersion of individual asset returns. During periods of high market price fluctuations, investors may react more uniformly, showing a herd effect. Such behavior may increase the correlation between asset returns, and the corresponding dispersion between returns will increase with the decline of market returns or at least at a rate lower than the proportion. For this reason, "the nonlinear market return $\mathrm{R} 2 \mathrm{~m}, \mathrm{t}$ is included in the test equation, and the significant negative coefficient $\gamma 3$ in the empirical test will be consistent with the occurrence of herd behavior.'[4].

\section{DISCUSSION}

The Chinese stock market is a large emerging market with plenty of individual investors. Theoretically, herd behavior exists so long as irrational investors exist.
Therefore, there is a high probability that herding exists in the Chinese stock market.

Based on previous studies of herding in the Chinese stock market, many researchers showed evidence of the presence of herd behavior based on the theory of the $\mathrm{CH}$ and CCK model (or modified $\mathrm{CH}$ and $\mathrm{CCK}$ model). Recognizing there were some studies find no evidence of herding within certain periods. These studies' chosen period of data is relatively short, hence, not so convincing. Oppositely, the papers that discovered apparent evidence of herd behavior are covering a wide range of time using daily, weekly and monthly frequency seperately. Tentatively, we can conclude that herd behavior is a prevalent phenomenon in China in the last two decades, although in short times there might not exist clear evidence of herding.

As to the impact of herding, it is not easy to identify yet. Some researchers believe herding is causing a greater deviation towards the stock market while others believe herding is good for the formation of an efficient market. In the context of China, we must acknowledge the negative effects caused by herding, including unnormal deviation caused by irrational investments made by plenty of noise traders, causing great individual loss. Also, it is important to think of the underlying reason why the Chinese stock market can develop at a relatively steady pace with the coexistence of a substantial amount of noise traders and herd behavior. Besides, the Chinese finance market is developing at a high speed. Its size and structure are changing constantly alongside. Herding is playing an important role in investments, but it is hard to predict whether it will have a positive effect on the Chinese stock market in the future.

\section{CONCLUSION}

China is a peculiar example to study herd behavior. China has the largest emerging market in the world, and it has a considerably high ratio of individual investors, which is, in most cases, consist of a lot of noise traders. China is one of those regions. In these regions consisting of noise traders, there exist problems including information lack of transparency, low efficiency caused by noise trading, the market value of stock deviated from its intrinsic value, and the high ratio of noise traders. Meanwhile, the Chinese stock market has an advantage due to its size and growth prospects. Former studies showed the existence of herd behavior in Chinese stock market. Existing problems could be the reason for herding in Chinese stock market, and its superiority stands for the perspective that herding is good for market efficiency. However, the stock price deviation could be influenced by a variety of factors other than herding, and it is impossible to identify all of the influential factors. That means herding detected based on the deviation of stock price could be inaccurate. We haven't investigated the reason behind the emerging of herding behavior in 
Chinese stock market in detail, hence, it could be the next step of the research.

\section{ACKNOWLEDGMENT}

I would like to express my special thanks of gratitude to Professor Colleen Honigsberg, who offered valuable advices to my research paper during the project.

I also want to show my gratitude to my father, who helped me gathering different information, collecting data and guide me from time to time as I learnt a great deal of new knowledge but having no idea how to use them in a proper way.

And I would also like to thank my friends who helped me a lot in finalizing this paper within the limited time frame.

\section{REFERENCES}

[1] Christie, W. G., \& Huang, R. D. (1995). Following the pied piper: Do individual returns herd around the market? Financial Analysts Journal, 51(4), 31-37. https://doi.org/10.2469/faj.v51.n4.1918 .

[2] Chang, E. C., Cheng, J. W., \& Khorana, A. (2000). An examination of herd behavior in equity markets: An international perspective. Journal of Banking \& Finance, 24(10), 1651-1679. https://doi.org/10.1016/s0378-4266(99)00096-5 .

[3] Chiang, T. C., \& Zheng, D. (2010). An empirical analysis of herd behavior in Global Stock Markets. Journal of Banking \& Finance, 34(8), 1911-1921. https://doi.org/10.1016/j.jbankfin.2009.12.014 .

[4] Chong, T. T.-L., Liu, X., \& Zhu, C. (2017). What explains herd behavior in the Chinese stock market? Journal of Behavioral Finance, 18(4), 448-456. https://doi.org/10.1080/15427560.2017.1365365 .

[5] Demirer, R., \& Kutan, A. M. (2010). The behavior of crude oil spot and futures prices around OPEC and SPR announcements: An event study perspective. Energy Economics, 32(6), 1467-1476. https://doi.org/10.1016/j.eneco.2010.06.006 .

[6] Chiang, T. C., Li, J., \& Tan, L. (2010). Empirical investigation of herding behavior in Chinese stock markets: Evidence from quantile regression analysis. Global Finance Journal, 21(1), 111-124. https://doi.org/10.1016/j.gfj.2010.03.005 .

[7] Black, F. (1986), Noise. The Journal of Finance, 41: 528-543. https://doi.org/10.1111/j.15406261.1986.tb04513.x.

[8] Zhang, Y. \& Xiaosong, Z (2016). A Study of Herd Behavior Based on the Chinese Stock Market, Journal of Applied Management and
Investments, Department of Business Administration and Corporate Security, International Humanitarian University, vol. 5(2), pages 131-135, May.

[9] Fu, T. (2010). Herding in China equity market. International Journal of Economics and Finance, 2(2). https://doi.org/10.5539/ijef.v2n2p148 .

[10] Spyrou, S. (2013). Herding in financial markets: A review of the literature. Review of Behavioural Finance, 5(2), 175-194. https://doi.org/10.1108/rbf02-2013-0009 .

[11] Bikhchandani, S., \& Sharma, S. (2000). Herd behavior in Financial Markets: A Review. SSRN Electronic Journal. https://doi.org/10.2139/ssrn.228343 .

[12] HIRSHLEIFER, D. A. V. I. D., SUBRAHMANYAM, A. V. A. N. I. D. H. A. R., \& TITMAN, S. H. E. R. I. D. A. N. (1994). Security analysis and trading patterns when some investors receive information before others. The Journal of Finance, $\quad 49(5)$, 1665-1698. https://doi.org/10.1111/j.15406261.1994.tb04777.x .

[13] Hirshleifer, D., \& Hong Teoh, S. (2003). Herd behaviour and cascading in Capital Markets: A review and synthesis. European Financial Management, 9(1), 25-66. https://doi.org/10.1111/1468-036x.00207 . 